Russel, A. J. F., Doney, J. M. \& Reid, R. L. (1967b). Y. agric. Sci., Camb. 68, 359.

Russel, A. J. F., Gunn, R. G. \& Doney, J. M. (1968). Anim. Prod. xo, 43.

Wallace, L. R. (r96r). Proc. Ruakura Fmrs' Conf. Week p. 14.

\title{
Hill pastoral resources and sheep production
}

\section{By JoHn Eadie, Hill Farming Research Organisation, 29 Lauder Road, Edinburgh EH9 $2 \mathcal{Y Q}$}

Hill sheep farming in the UK takes place in a wide range of hill environments. They differ climatically, and in their soils and vegetation. Management practices vary from one hill farming region to another, as do breeds of sheep.

A major feature of hill sheep production is its low output per unit area. Output of saleable weaned lamb live weight, for example, ranges from less than $3.5 \mathrm{~kg} / \mathrm{ha}$ ( $3 \mathrm{lb} / \mathrm{acre}$ ) per annum in the poorer (but not the poorest) hill environments, to upwards of $35 \mathrm{~kg} / \mathrm{ha}$ ( $3 \circ \mathrm{lb} /$ acre) per annum in the better ones.

For many decades the low output of hill sheep farming was matched by an appropriately low-cost structure. But, since the mid 1950's costs have increased sharply due, in the main, to increases in costs of labour. Increases in costs of labour bear heavily on hill sheep production since they amount to some $30-40 \%$ of total costs. Over the same period the prices of store lambs and cast ewes have remained static. The consequence has been that, despite the changes in the value of the $f$ over that period, the net profit per farm has not improved, while government support has risen from around $60-70 \%$ to $130-190 \%$ of the net profit (Duthie, I968).

The important point for the future is that costs of labour are likely to continue to increase at a faster rate than prices. One approach to the problem would be to attempt to reduce costs; this may be possible in some instances in the short term but it will not provide a general long-term solution.

A much more meaningful approach is to attempt to develop systems of hill sheep production within which unit costs of production will be significantly reduced. Equally important is the need to do this in such a way as to provide opportunities, extending well into the future, for reacting to economic change and technical advance. This, in effect, requires the establishment of a production framework within which, in the longer if not in the short term, substantial increases in output are possible. Basic to any progress in this direction is an adequate biological understanding of the processes of production. But, biological and economic efficiencies are not necessarily coincident. It is therefore necessary to employ the consequences of that biological understanding within an economic framework with the constraints that this implies.

The low outputs of sheep products of existing systems of hill sheep production are a function of low stocking rates and of poor levels of sheep performance. Some $65 \%$ of the hill sheep in Scotland are stocked at rates of between one sheep per 0.8 
ha ( 2 acres) and one per 2 ha ( 5 acres) (Cunningham, Smith \& Doney, 1971). Weaning percentages range from less than 60 to over 100 , and weaning weights of lambs around 16 weeks of age vary from under $18 \mathrm{~kg}(40 \mathrm{lb})$ to over $27 \mathrm{~kg}(60 \mathrm{lb})$ depending to some extent on breed, but to a much greater extent on nutritional environment.

\section{Pasture production and utilization}

In attempting to account for these low levels of animal output the obvious starting point is that of pasture primary production. Yields of hill pastures are poorly documented, but on the basis of work in the Hill Farming Research Organisation and elsewhere, (Anonymous, 1970), a reasonable summary, adequate for present purposes, can be made. The most productive hill grasslands, the Agrostis-Festuca pastures, which on the best grassy hills may amount to some $25-30 \%$ of the total area of a hill grazing, yield some $2200-275^{\circ} \mathrm{kg}$ dry matter/ha per annum with the best of them approaching $3200 \mathrm{~kg}$ dry matter/ha per annum. Molinia- and Nardus-dominant hill pastures are less productive, producing $1300-1750 \mathrm{~kg}$ dry matter/ha. The annual yield of the supposedly edible material of heather varies from 1000 to $2500 \mathrm{~kg} / \mathrm{ha}$ per annum.

Thus, the mean annual yield of pasture dry matter on a hill grazing is likely to be some $20-30 \%$ of that of a lowland pasture receiving around $100 \mathrm{~kg}$ nitrogen/ha per annum.

The first point of importance to be made is that although there is a threefold to fivefold difference in levels of pasture production between the hills and the lowlands this only goes a small way towards explaining the very large difference (of around fortyfold) in sheep production.

In pursuing this problem further it is convenient to consider the process of converting hill pasture production to saleable sheep product in two stages. The first stage is that of the efficiency with which the pasture production is ingested by the sheep population. It would be generally agreed that in a moderately intensive, well-managed, lowland sheep production-system some $60-70 \%$ of the pasture production would actually be eaten by the sheep. On the hills, however, an average value, calculated on the basis of a hill grazing producing some $2000 \mathrm{~kg}$ dry matter $/ \mathrm{ha}$ per annum, an annual dry-matter intake per ewe of $500 \mathrm{~kg}$ and a stocking rate of 0.8 ewes/ha, would be in the region of $20 \%$.

The second stage is that of the efficiency with which the ingested dry matter is converted to weaned lamb live weight. A calculation, based on a hill ewe eating $500 \mathrm{~kg}$ dry matter/annum, in a flock weaning $80 \%$ of lambs averaging $24 \mathrm{~kg}$ each would be $3.8 \mathrm{~kg}$ weaned lamb live weight per roo kg pasture dry matter ingested. A similar calculation for a lowland flock weaning $170 \%$ of lambs of average weight $36.0 \mathrm{~kg}$ with each ewe eating some $720 \mathrm{~kg}$ dry matter/annum would be $8.5 \mathrm{~kg}$ weaned lamb per $100 \mathrm{~kg}$ pasture dry matter ingested.

Therefore, although pasture production is markedly poorer in the hills than in the lowlands this only accounts in part for the comparatively low output of animal product in hill sheep farming. Hill pasture production is utilized at only a fraction of 
the efficiency with which lowland pasture production is utilized, in part because the major part of it is not eaten at all, and in part because that which is eaten is converted to animal product with roughly half the efficiency of lowland sheep production.

\section{The production process}

Hill pasture production is highly seasonal; there is no pasture growth at all for roughly 6 months of the year. In fact, the fund of available herbage is declining during this period due to the processes of plant death and decay. During the growing season the daily increment of growth varies considerably.

Against this background of highly seasonal pasture production, hill sheep flocks are normally set-stocked in a year-round grazing system. Stocking rates are set at levels which will ensure a certain minimum level of winter nutrition from grazed pasture. The fund of pasturage from which this must be provided contains a large proportion of dead material of very poor quality (Eadie \& Black, I968), so that the fund itself is poorly utilized.

Stocking rates set in this way are consequently very low with respect to levels of pasture production during the summer. A substantial proportion of the pasture production, particularly at the peak of the growing season in June and July, remains ungrazed. The ungrazed herbage accumulates, its nutritive value declines and the fund of material conserved in situ, so to speak, already contains at the onset of winter a large proportion of poor quality herbage. The extent to which this accumulated fund can be utilized in winter, consistent with the necessary minimum level of nutrition, is very limited and so the vicious circle goes on.

The process leads to a cyclical pattern of nutrition and one such cycle has been described (Eadie, 1967 ). It might be thought that the low grazing pressures which obtain in early summer would, through the high degree of opportunity for diet selection to which they give rise, provide pasture intakes of high quality at that time. This is not so on grassy hill pastures because diet selection in early summer is from a fund of material which contains a good deal of poor quality herbage carried over from the previous growing season (Eadie $\&$ Black, 1968). Ingested pasture quality throughout the remainder of the annual cycle is similarly depressed, and the general result is both poor pasture utilization and poor year-round nutrition.

All of this is in marked contrast to events in lowland sheep production-systems, in which stocking rates are set at levels which relate much more closely to summer pasture production (Eadie, 1970). This is made possible because pasture growth surplus to summer grazing requirements can be cut, conserved and fed back in winter. Conservation by means of hay or silage is a much more efficient process than the conservation of uneaten herbage in situ. It also has the advantage that the surplus is removed and not left to deteriorate and reduce the grazing pressure at which satisfactory nutrition may be obtained at a future grazing.

It must be concluded that existing stocking rates and existing levels of sheep performance on the hills are, to an important extent, functions of the nature and 
consequences of the year-round, free range, set-stocked systems of hill grazing management.

\section{The improvement of output}

Although the nutritional deficiencies of any pastoral system may be eliminated, at least in part, by the use of supplementary feed (and some such supplementation may be necessary in any event), the real issue is to develop pastoral systems which will effectively harness the potential of the hills, and to create a nutritional background consonant with improved sheep performance and output.

On the basis of the analysis of the problem presented here three major possibilities are apparent. In the first place existing hill pasture production may be more efficiently utilized. This would require grazing control over at least a part of a hill grazing. Secondly, pasture production may be increased on at least a proportion of a hill grazing. Thirdly, a more radical solution would be to remove, either completely or in part, one of the root-causes of the problem, that of a major dependence on grazed pasture in winter, by the development of systems of production based on offwintering or in-wintering.

Economics. These are not mutually exclusive solutions. They do however all require capital investment and capital investments usually bring in their train increases in recurrent costs. Since improved systems require to be economically as well as biologically sound, a technique whereby the various technical possibilities can be examined in economic terms is necessary.

It is contended that an appropriate means of assessment in many instances is that of assessing the return to the marginal capital investment. Harkins (I 968 ) has developed a comparatively simple procedure based on a break-even budget technique for this purpose. This enables a calculation of the increase in output in terms of the various possible combinations of increase in stocking rate and improvements in performance of sheep it is necessary to promote in order to recoup various levels of capital investment and recurrent cost increases.

The relative importance of capital investment and recurrent costs in hill sheep farming can be gauged from some calculations which show that in general terms a $f_{0} 0.50$ increase in variable costs would require a $12 \%$ increase in per head performance to justify it. A similar increase in per head performance would service a $f_{1} \mathrm{r} 200-f_{1} \mathrm{r} 500$ investment in a flock of 500 ewes.

Year-round systems. In considering the first two possibilities it has to be borne in mind that the spectrum of variation in hill soils and vegetation is very great. It ranges from the Agrostis-Festuca grasslands found on acid brown earth soils, through Nardus- and Molinia-dominant pastures growing on peaty podsolic soils and heather (Calluna vulgaris (L.) Hull) moor, to the Calluna-Eriophorum vegetation of blanket bog.

A range of hill land improvement techniques are available whereby substantial improvements in pasture production can be obtained in all of these situations by soil upgrading and reseeding. But in the grass-dominant areas other possibilities exist. 
It has been shown that controlling the grazing of Agrostis-Festuca hill pastures can effect a marked reduction in the amount of dead, ungrazed, herbage normally carried on these pastures. The result is much improved utilization and better sheep nutrition (Eadie \& Black, r968). It is likely that applications of lime and phosphate would further enhance productivity, and that even greater improvement would accompany the introduction of clovers and, perhaps, grasses.

On the poorer types of grassy hill pasture, for example certain types of Moliniaand Nardus-dominant pastures, the effect of grazing control without the provision of lime and phosphate would be very slow and only of limited value, because vegetational change involving a marked reduction of the dominant species and their replacement by the better hill species (Agrostis spp., Festuca spp. and Deschampsia flexuosa Trin.) would be necessary. But a combination of grazing control and improvement in soil-base status would enhance the pace of desirable botanical change and, of course, these areas too are capable of responding to soils improvement and sown seeds.

On some hill grazings, then, a range of improvement possibilities are available and on others, upgrading of soils together with the introduction of new plant material is essential. Where there is a choice the best procedure is not necessarily that which produces the greatest increase in pasture productivity, but that which produces the best return for the expenditures involved. Currently, an expanding programme of work in the Hill Farming Research Organisation is aimed at providing the information on which cost-benefit judgments of this kind may be objectively made.

It is neither necessary nor is it possible for reasons of cost, topography and accessibility to envisage the improvement of the whole of a hill grazing. The improved hill grazing therefore consists of two parts, a relatively small area of improved pasture and a relatively large area of unimproved hill. The choice of the area to be improved and the method of improvement will be determined by the amount of capital available, the nature of the soils and vegetation, cost-benefit considerations, and by practical matters such as accessibility.

A key issue in such a two-pasture system is the integration of the two parts in a year-round management system. The important principle is to use the improved pasture area in such a way as to have it make its maximum impact on individual sheep performance. Russel (I97I) has dealt in detail with nutrition and performance in hill sheep, highlighting the importance of improved summer nutrition to both lamb growth and recuperation of ewe body condition. On present evidence the best compromise between these nutritional arguments on the one hand, and pasture growth and management considerations on the other, is that the limited quantities of better quality feed should be used in two important periods. The improved pasture area should be used as much as possible during lactation and lamb growth, and, following a mid season rest from mid August, during which the pasture regrowth is accumulated, again during the pre-mating and mating periods.

Within the new production framework other changes become necessary and some desirable changes become possible. For example where better reproductive performance is expected it becomes even more important to nourish ewes adequately 
in late pregnancy by making supplementary feeding a routine practice. The separation of early and late lambing ewes contributes both to a more efficient use of pre-lambing feed and to better control and supervision at lambing. It is more practical to carry out the necessary raddling of tups where mating takes place in enclosed pasture.

These and other husbandry changes, together with the need for greater efficiency of labour use, may require more elaborate stock control arrangements than those strictly necessary on the grounds of better pasture utilization. But what is required in this regard will depend upon the problems presented by individual hill grazings. The important point is that those measures dictated by the need to increase sheep output provide a framework within which it is possible to improve the efficiency of labour use.

Off-wintering systems. The third of the three major possibilities for increasing sheep production from hill pastures suggested earlier in this paper concerned offwintering. In theory the removal of the limitation imposed by grazed pasture dependence in winter should allow of stocking rates more consonant with rates of summer pasture production. But, the improvement of individual sheep performance requires better summer nutrition. The fact that nutrition during the off-wintering period can be controlled and manipulated is unlikely to lead to any significant improvement in sheep performance. It can therefore be argued that a combination of off-wintering and pasture improvement will have a much greater impact on total output than off-wintering alone.

A consideration of the economic issues involved tends to support this contention. The capital cost of an in-wintering house may or may not be necessary, but offwintering in any form greatly increases winter feeding costs, and these are likely to be in the region of $\mathfrak{f}_{2}$ per head. The importance of increased recurrent costs has already been stressed and a calculation based on average performance figures suggests that in many situations the output increase necessary to recoup those increased feed costs exceeds $100 \%$. In the absence of better summer nutrition provided by improved pasture this increase would have to be obtained largely from an increased stocking rate. But a further calculation suggests that an improvement in individual sheep output of $20 \%$ would have the effect of halving the required stocking-rate increase.

\section{Development}

These various ideas imply sheep production systems markedly different in many important respects to those now current in hill sheep farming. The ideas require integration into whole systems of production which in turn require development and economic assessment. A programme of development work has been initiated in the Hill Farming Research Organisation for those purposes in recent years. The current programme includes two major kinds of investigation, year-round grazing systems and off-wintering (in-wintering) systems.

Two year-round grazing studies are now in being. Common to both is the integration of areas of improved pasture with the remaining unimproved open hill in 
such a way as to maximize the impact of the available improved pasture on sheep performance. The major difference between the two studies is that they take place in widely contrasting hill environments, one on a predominantly grassy hill grazing and one on blanket peat. The land improvement techniques are those appropriate to each of the environments. Because some of the problems encountered in developing whole systems of production are problems of scale these studies are carried out in areas of land of $280-400$ ha (700-1000 acres) and involve sheep flocks of around $400-500$ ewes.

Two in-wintering studies are also being carried out in each of the two environments. The key questions they are designed to answer, among others, concern the consequences of off-wintering with respect to the interrelationship of stocking rate and performance as stocking rates are increased towards the economic break-even point in each hill environment; and the impact of improved pasture, (integrated in line with the arguments advanced in relation to the use of such pasture in yearround systems, with the unimproved hill) on sheep performance in an off-wintering system.

Each of these off-wintering studies comprises two interrelated systems which are run on contiguous areas of hill land of similar character. The sheep flocks are of the same size, breed and breeding and are in-wintered similarly in the same sheephouse. The difference between the two parts of each study is that one of them includes an area of improved pasture and the other does not. The intention is to double the stocking rate over a 5 -year period and the rate of increase will be applied equally to both parts.

All of the information necessary to the economic evaluation of this work is being collected, and at the same time, in order to make extrapolation of the findings to other situations with any degree of certainty possible, monitoring of the various aspects of the biology of these systems is being carried out. A more detailed account of this work and a discussion of some of the important issues involved in systems development work in hill sheep production can be found elsewhere (Eadie, I 971).

Some of this work has been under way for just over 2 years and much of the programme is of more recent origin. It is in the nature of this activity that it is fairly long term and at this point in time it would be premature, and perhaps misleading, to discuss the early results.

\section{REFERENCES}

Anonymous (1970). In Hill Sheep Farming Today and Tomorrow. Agricultural Adjustment Unit Bull. no. 13, p. 36. Newcastle upon Tyne: University of Newcastle upon Tyne.

Cunningham, J. M. M., Smith, A. D. M. \& Doney, J. M. (1971). Rep. Hill Fmg Res. Org, no. 5, p. 88.

Duthie, W. B. (1968). Bull. Edinb. Sch. Agric, no. 90.

Eadie, J. (1967). Rep. Hill Fmg Res. Org. no. 4, p. 38.

Eadie, J. (1970). In Animal Populations in Relation to their Food Resources p. 7 [A. Watson, editor]. Oxford and Edinburgh: Blackwell Scientific Publications.

Eadie, J. (1971). Rep. Hill Fmg Res. Org. no. 5, p. 70.

Eadie, J. \& Black, J. S. (1968). In Hill Land Productivity p. 191 [1. V. Hunt, editor]. Ayr: British Grassland Society.

Harkins, J. (1968). Scott. F. Agric. 47, 196.

Russel, A. J. F. (1971). Proc. Nutr. Soc. 30, 197. 